\title{
BMJ Open Disparities in the receipt of robot-assisted radical prostatectomy: between-hospital and within-hospital analysis using 2009-2011 California inpatient data
}

\author{
Jungyoon Kim, ${ }^{1}$ Wael EIRayes, ${ }^{1}$ Fernando Wilson, ${ }^{1}$ Dejun $\mathrm{Su},{ }^{2}$ Dmitry Oleynikov, ${ }^{3}$ \\ Marsha Morien, ${ }^{1}$ Li-Wu Chen ${ }^{1}$
}

To cite: Kim J, ElRayes W, Wilson $\mathrm{F}$, et al. Disparities in the receipt of robot-assisted radical prostatectomy: between-hospital and withinhospital analysis using 2009-2011 California inpatient data. BMJ Open 2015;5: e007409. doi:10.1136/ bmjopen-2014-007409

- Prepublication history and additional material is available. To view please visit the journal (http://dx.doi.org/ 10.1136/bmjopen-2014007409).

Received 9 December 2014 Revised 14 March 2015 Accepted 26 March 2015

CrossMark

\section{${ }^{1}$ Department of Health Services Research \& Administration, University of Nebraska Medical Center, Omaha, Nebraska, USA ${ }^{2}$ Department of Health Promotion, Social and Behavioral Health, Center for Reducing Health Disparities, University of Nebraska Medical Center, Omaha, Nebraska, USA \\ ${ }^{3}$ Center for Advanced Surgical Technology, University of Nebraska Medical Center, Omaha, Nebraska, USA}

Correspondence to Jungyoon Kim; Jungyoon.kim@unmc.edu

\section{ABSTRACT}

Objectives: Despite the rapid proliferation of robotassisted radical prostatectomy (RARP), little attention has been paid to patient utilisation of this newest surgical innovation and barriers that may result in disparities in access to RARP. The goal of this study is to identify demographic and economic factors that decrease the likelihood of patients with prostate cancer (PC) receiving RARP.

Design, setting and participants: A retrospective, pooled, cross-sectional study was conducted using 2009-2011 California State Inpatient Data and American Hospital Association data. Patients who were diagnosed with $\mathrm{PC}$ and underwent radical prostatectomy (RP) from 225 hospitals in California were identified, using ICD-9-CM diagnosis and procedure codes.

Primary outcome measures: Patients' likelihood of receiving RARP was associated with patient and hospital characteristics using the two models:

(1) between-hospital and (2) within-hospital models. Multivariate binomial logistic regression was used for both models. The first model predicted patient access to RARP-performing hospitals versus non-RARPperforming hospitals, after adjusting for patient and hospital-level covariates (between-hospital variation). The second model examined the likelihood of patients receiving RARP within RARP-performing hospitals (within-hospital variation).

Results: Among 20411 patients who received RP, $13750(67.4 \%)$ received RARP, while 6661 (32.6\%) received non-RARP. This study found significant differences in access to RARP-performing hospitals when race/ethnicity, income and insurance status were compared, after controlling for selected confounding factors (all $p<0.001$ ). For example, Hispanic, Medicare and Medicaid patients were more likely to be treated at non-RARP-performing hospitals versus RARPperforming hospitals. Within RARP-performing hospitals, Medicaid patients had $58 \%$ lower odds of receiving RARP versus non-RARP (adjusted OR 0.42, $p<0.001$ ). However, there were no significant differences by race/ ethnicity or income within RARP-performing hospitals. Conclusions: Significant differences exist by race/ ethnicity and payer status in accessing RARP-performing

\section{Strengths and limitations of this study}

- The study captured both supply factors (hospital capability of performing robotic surgery) and demand factors (patient demographic and economic characteristics) that may have differential impacts on the utilisation of robot-assisted radical prostatectomies, which were not previously examined.

- The study used a comprehensive database containing all inpatient records in the State of California (USA) from 2009 to 2011. However, these study results should be generalised with caution for other states within the USA or other countries.

- This study used a cross-sectional design, and lacked clinical history and biomarker data on patients undergoing radical prostatectomies.

hospitals. Furthermore, payer status continues to be an important predictor of receiving RARP within RARPperforming hospitals.

\section{INTRODUCTION}

Robot-assisted radical prostatectomy (RARP) has been widely accepted by the urological society for the past 15 years. From 2005 to 2008, the number of RARPs increased from 9000 to $58000 .^{1}$ In 2010 , it was estimated that $69-85 \%$ of all radical prostatectomy (RP) cases in the USA were performed robotically. ${ }^{2}$ Robotic surgery has the potential to improve processes and patient outcomes by helping younger novice surgeons learn to perform minimally invasive RP within a relatively short period of time. ${ }^{3}$ Research suggests that robotic surgery may improve patient outcomes, such as reduced blood loss, shorter length of hospital stay, lower risk of mortality, lower surgical complications, 
and faster recovery. ${ }^{4-8}$ Thus, this advanced surgical technology (ie, RARP) has been widely utilised in US healthcare, in spite of its higher costs, compared with open RP (ORP) and conventional laparoscopic RP (LRP). ${ }^{8}$

Racial and socioeconomic disparities have been well documented in the field of prostate cancer (PC) management/treatment. ${ }^{9-12}$ To the best of our knowledge, however, only one study has examined racial and socioeconomic disparities in access to an RARP-performing hospital. ${ }^{13}$ The previous study was conducted in between-hospital comparison, by examining RP patients' access to hospitals with robotic technology versus hospitals without robotic technology. This is a legitimate approach because RARP is a highly equipment-intensive procedure, meaning that patients will not undergo RARP if they do not have access to the hospitals with robotic technology. Several studies have confirmed that the use of RARP is centralised within a few large, primarily academic, hospitals that are located in urban areas where racial and socioeconomic minorities have less access to those facilities. ${ }^{14-16}$ Thus, we conducted between-hospital analysis to identify demographic and economic factors that influence patients' access to RARP-performing hospitals using all inpatient data relating to California.

However, patients with access to hospitals that have robotic technology may undergo different options of surgical treatment, including ORP, LRP and RARP. Current studies have not addressed whether the racial and socioeconomic differences exist in the use of RARP once the hospital-level access barrier is removed. Therefore, we extended current research by also examining within-hospital differences in the receipt of RARP versus non-RARP. Furthermore, we examined other patient-level characteristics, such as payer type, that may be important predictors of the receipt of RARP. Our study used a comprehensive database containing nearly all inpatient records for the State of California in order to assess whether there were systematic, between-hospital differences as well as within-hospital differences by race/ ethnicity and socioeconomic status in patients' access to RARP.

\section{MATERIALS AND METHODS}

\section{Data source}

We used the 2009-2011 California State Inpatient Database (SID) and the 2009 American Hospital Association Annual Survey Database. The SID is a component of the Healthcare Cost and Utilization Project sponsored by the Agency for Healthcare Research and Quality, and provides comprehensive data on hospital inpatient stays in each state. ${ }^{17}$ The AHA Annual Survey Database is a comprehensive hospital database of over 6500 hospitals in the USA and contains up to 1000 fields of information, including facility size, teaching status, service lines, inpatient and outpatient utilisation, and expenses. $^{18}$

\section{Study population}

The study population included all patients who received RP for PC from 2009 to 2011 in California. To determine our analytic cohort, we first identified patients who had a primary diagnostic International Classification of Disease, 9th revision, Clinical Modification (ICD-9-CM) code for PC (185). We then identified patients with a primary procedure code for RP (60.5) and secondary procedure codes for any type of robotic intervention $(17.41,17.42,17.43$, 17.44, 17.45 and 17.49). To identify hospital characteristics, the California SID was merged with the 2009 AHA database. This approach identified 20411 patients who were diagnosed with PC and who received RP in 225 hospitals in California for the study period 2009-2011. Of these, 18101 patients had non-missing information on age, race/ethnicity, primary payer, patients' place of residence and median ZIP code income.

\section{Primary outcome}

We used two dependent variables: (1) a hospital-level binary variable of RARP-performing versus non-RARPperforming and (2) an individual-level binary variable of receiving or not receiving RARP. Thus, the first model examines availability of RARP across hospitals, and the second model examines determinants of patient receipt of RARP within RARP-performing hospitals.

\section{Patient and hospital characteristics}

Patient demographic information included age, race/ ethnicity, primary payer, patients' place of residence (metro vs non-metro), and median ZIP code income by quartile. Age was categorised as one of four groups: younger than 55, 55-64, 65-74, and 75 years and older. Race/ethnicity was categorised as non-Hispanic white, black or African-American, Hispanic and other (Asian or Pacific Islander, Native American and other). The patients' primary payer was grouped into four main categories: private insurance, Medicare, Medicaid, and other (self-pay, no charge, worker's compensation, or other government and/or county indigent programmes). We used the 2003 version of the Rural-Urban Continuum Codes to classify metro and non-metro areas. Metro areas were defined as counties in metropolitan areas with the size of 1 million people or more, 250000 to 1 million people, and below 250000 . Non-metro areas were defined as counties with urban population of 20000 or more, 2500-19 999, and completely rural areas or less than 2500 urban populations. Median household income based on patient's ZIP code was separated into four quartiles. Quartiles were identified by values of 1 (the lowest quartile) to 4 (the highest quartile), indicating the poorest to wealthiest populations, respectively. The cut-offs for the quartile designation are determined using ZIP code demographic data obtained from Claritas. ${ }^{19}$

The study also included the Elixhauser comorbidity index, consisting of 29 coexisting medical conditions. ${ }^{20}$ Medical conditions were coded 1 if the comorbidity was 
present, or 0 if not present. We used the sum of all the comorbidity measures for the analysis. The three categories were added in the model: 0 (zero) comorbidities, 1 comorbidity and 2 or more comorbidities.

Three hospital characteristics were selected and added to the model based on previous studies. ${ }^{413}$ Ownership status was divided into three groups: for-profit (investor-owned), not-for-profit (religious or non-religious not-for-profit) and public/government (federal-owned or state/county-owned hospitals). Hospital teaching status (teaching and nonteaching) and bed size (0-399 and 400 or more beds) were also added to the model.

\section{Statistical analysis}

We obtained descriptive statistics of patient and hospital characteristics among all hospitals and for RARP-performing hospitals. Pearson's $\chi^{2}$ test was used to examine associations across different subgroups. This analysis was followed by multivariate logistic regression analyses examining whether patient and hospital characteristics were associated with (1) adjusted odds of accessing a RARP-performing hospital, and (2) adjusted odds of patients with PC receiving RARP within an RARP-performing hospital. A p value $<0.05$ denoted statistical significance. SAS V.9.3 was used to perform all statistical analyses.

\section{RESULTS}

Table 1 summarises 20411 RP patient and hospital characteristics by RARP-performing versus non-RARPperforming hospitals. The number and trend of RARP cases during the study period are illustrated in the online supplementary table S1. Among 225 hospitals that performed at least one RP during the 3-year study period, 73 performed RARP and 152 did not perform RARP. RARP-performing hospitals had a higher proportion of patients who were non-Hispanic whites $(71.0 \%$ vs $57.7 \%, \mathrm{p}<0.001)$, private payers $(62.5 \%$ vs $53.7 \%$, $\mathrm{p}<0.001)$, and resided in the highest ZIP code income areas $(37.3 \%$ vs $23.5 \%, \mathrm{p}<0.001)$. More RP patients in RARP-performing hospitals had zero comorbidities $(40.3 \%$ vs $32.7 \%, \mathrm{p}<0.001)$ and lived in metro areas (97.8\% vs $96.4 \%, \mathrm{p}<0.001)$ compared with RP patients in non-RARP-performing hospitals. RARP-performing hospitals were more likely to have not-for-profit ownership $(71.2 \%$ vs $60.9 \%, \mathrm{p}=0.01)$, larger bed size $(30.1 \%$ vs $5.3 \%, \mathrm{p}<0.001)$ and teaching status $(20.5 \%$ vs $3.3 \%$, $\mathrm{p}<0.001)$.

Table 2 summarises $16421 \mathrm{RP}$ patient characteristics by receipt of RARP versus receipt of non-RARP within the 73 RARP-performing hospitals. No significant between-group differences were found by age $(p=0.15)$, race/ethnicity $(\mathrm{p}=0.36)$, median household income $(\mathrm{p}=0.80)$, Elixhauser comorbidity index $(\mathrm{p}=0.36)$ or metro/non-metro category $(p=0.78)$. However, significant differences were found by insurance status between patients who did versus those who did not receive RARP
(63.1\% vs $59.8 \%$ for private insurance; $1.4 \%$ vs $2.7 \%$ for Medicaid, respectively; $\mathrm{p}<0.001$ ).

Table 3 shows results from the multivariate logistic regression analysis for both models. Model 1 examined the association of patient and hospital characteristics and the likelihood of accessing an RARP-performing hospital. The final sample for model 1 included 18101 RP patients from 225 hospitals in California during the 3-year time period. Patients' race/ethnicity, socioeconomic status and payer type were associated with the likelihood of accessing an RARP-performing hospital, after adjusting for selected confounding factors. More specifically, Hispanics (adjusted OR (AOR) 0.63; $\mathrm{p}<0.001$ ), Medicare and Medicaid beneficiaries, as well as other self-paid or government subsidy dependents (AOR 0.71, 0.14, and 0.09 , respectively; $\mathrm{p}<0.001$ for all) were less likely to access an RARP-performing hospital, compared with privately paid patients. Additionally, compared with patients who lived in the lowest median household income area, those residing in a higher income area were more likely to access a RARP-performing hospital (AOR 1.17, 1.26, and 1.90 by ascending order of income quartile; $p=0.02$, $<0.001$ and $<0.001$, respectively). Compared with patients without comorbidities, patients who had a higher number of comorbidities were less likely to access a RARP-performing hospital (AOR 0.54, p<0.001). Relative to metro residence, non-metro residence was associated with lower odds of accessing an RARP-performing hospital (AOR 0.28, $\mathrm{p}<0.001$ ). At the hospital level, government hospitals (AOR 1.23, $\mathrm{p}=0.003$ ), teaching hospitals (AOR 4.75, $\mathrm{p}<0.001$ ), and larger hospitals with 400 beds or more (AOR 7.06, $\mathrm{p}<0.001$ ) were more likely to be an RARP-performing hospital compared with not-for-profit, non-teaching, and smaller hospitals with 399 beds or less.

Whereas model 1 analysed the likelihood of patients with PC receiving RP at an RARP-performing versus a non-RARP performing hospital, model 2 examined patients' likelihood of receiving robotic surgery within RARP-performing hospitals. Thus, model 2 identifies socioeconomic, payer status and other factors that may predict receiving RARP versus ORP or LRP. The sample for model 2 consisted of 14679 patients from 73 hospitals. Hospitals included in model 2 performed at least one RARP during the study period. After controlling for selected patient demographics and hospital characteristics, within-hospital analysis revealed that age, race/ethnicity and income (except for the third quartile, ie, the middle-high income group) were no longer significant predictors of receiving RARP. However, we found that significantly and consistently, Medicaid beneficiaries had $58 \%$ lower adjusted odds of receiving RARP, compared with those with private insurance (AOR 0.42; $\mathrm{p}<0.001$ ). Having two or more comorbidities was associated with a lower likelihood of receiving RARP relative to patients with no comorbidities (AOR 0.80, p<0.001). Investor-owned and government-owned hospitals were $60 \%$ and $49 \%$ less likely, respectively, to perform RARP compared with not-for-profit hospitals (AOR 0.40 and 0.51, 
Table 1 Patient and hospital characteristics (model 1)

\begin{tabular}{|c|c|c|c|c|}
\hline Variables & $\begin{array}{l}\text { All } \\
\text { hospitals }\end{array}$ & $\begin{array}{l}\text { Non-RARP-performing } \\
\text { hospitals }\end{array}$ & $\begin{array}{l}\text { RARP-performing } \\
\text { hospitals }\end{array}$ & $\begin{array}{l}\text { p } \\
\text { Value* }\end{array}$ \\
\hline Number of hospitals & 225 & 152 & 73 & \\
\hline Number of patients (\%) & 20411 & 3990 (19.5) & $16421(80.5)$ & \\
\hline \multicolumn{5}{|l|}{ Patient characteristics } \\
\hline Age (\%) & & & & 0.007 \\
\hline Younger than 55 & 3308 (16.4) & $595(15.1)$ & 2713 (16.8) & \\
\hline $55-64$ & 8564 (42.5) & 1747 (44.4) & 6817 (42.1) & \\
\hline $65-74$ & 7628 (37.9) & 1491 (37.9) & 6137 (37.9) & \\
\hline 75 or older & $631(3.1)$ & $106(2.7)$ & $525(3.2)$ & \\
\hline Race (\%) & & & & $<0.001$ \\
\hline Non-Hispanic white & $12746(62.5)$ & $2020(57.7)$ & $10726(71.0)$ & \\
\hline Non-Hispanic black & $1537(7.5)$ & $316(9.0)$ & $1221(8.0)$ & \\
\hline Hispanic & $2790(13.7)$ & $888(25.4)$ & $2790(12.6)$ & \\
\hline Other & $1529(7.5)$ & $278(7.9)$ & $1251(8.3)$ & \\
\hline Primary insurance (\%) & & & & $<0.001$ \\
\hline Private & $12411(60.8)$ & $2142(53.7)$ & $10269(62.5)$ & \\
\hline Medicare & 6995 (34.3) & $1397(35.0)$ & $5598(34.1)$ & \\
\hline Medicaid & $473(2.3)$ & $216(5.4)$ & $257(1.6)$ & \\
\hline Other† & $532(2.6)$ & $235(5.9)$ & $297(1.8)$ & \\
\hline Median household income (\%) & & & & $<0.001$ \\
\hline Lowest quartile & 3252 (15.9) & $866(22.2)$ & 2386 (14.9) & \\
\hline Middle-low quartile & 4269 (20.9) & 1009 (25.9) & 3260 (20.4) & \\
\hline Middle-high quartile & 5487 (26.9) & $1105(28.4)$ & $4382(27.4)$ & \\
\hline Highest quartile & 6877 (33.7) & 915 (23.5) & 5962 (37.3) & \\
\hline Comorbidity index (\%) & & & & $<0.001$ \\
\hline 0 & 7917 (38.8) & 1305 (32.7) & $6612(40.3)$ & \\
\hline 1 & 6909 (33.9) & 1326 (33.2) & $5583(34.0)$ & \\
\hline 2 or Greater & $5585(27.4)$ & $1359(34.1)$ & $4226(25.7)$ & \\
\hline Place of residence (\%) & & & & $<0.001$ \\
\hline Metro & $19818(97.3)$ & $3803(96.4)$ & $16015(97.8)$ & \\
\hline Non-metro & $549(2.7)$ & $180(3.6)$ & $369(2.2)$ & \\
\hline Year & & & & $<0.001$ \\
\hline 2009 & $6667(32.7)$ & 1593 (39.9) & $5074(30.9)$ & \\
\hline 2010 & 6590 (32.3) & 1271 (31.9) & 5319 (32.4) & \\
\hline 2011 & $7154(35.1)$ & $1126(28.2)$ & $6028(36.7)$ & \\
\hline \multicolumn{5}{|l|}{ Hospital characteristics } \\
\hline Ownership (\%) & & & & 0.01 \\
\hline Not-for-profit & $144(64.3)$ & $92(60.9)$ & $52(71.2)$ & \\
\hline For-profit & $40(17.9)$ & 35 (23.2) & $5(6.8)$ & \\
\hline Government & 40 (17.9) & $24(15.9)$ & $16(21.9)$ & \\
\hline Teaching status $\ddagger$ (\%) & & & & $<0.001$ \\
\hline Non-teaching & $204(91.1)$ & $147(96.7)$ & $58(79.5)$ & \\
\hline Teaching & $20(8.9)$ & $5(3.3)$ & $15(20.5)$ & \\
\hline Hospital bed size (\%) & & & & $<0.001$ \\
\hline 0-399 & $194(86.6)$ & $144(94.7)$ & $51(69.9)$ & \\
\hline 400 and more & $30(13.4)$ & $8(5.3)$ & $22(30.1)$ & \\
\hline
\end{tabular}

${ }^{*}$ Pearson's $\chi^{2}$ test was conducted to test the proportional difference between RARP-performing hospitals and non-RARP-performing hospitals for each subpopulation.

†Other insurance includes self-pay, no charge, worker's compensation, or other government and/or county indigent programmes.

¥Teaching status was obtained from the AHA annual survey 2009 (member of the Council of Teaching Hospitals of the Association of American Medical Colleges.

RARP, Robot-assisted radical prostatectomy.

respectively, $\mathrm{p}<0.001$ for both). Teaching hospitals were more likely than non-teaching hospitals to employ robotic surgery in treating patients with PC (OR 1.65, $\mathrm{p}<0.001)$. Interestingly, we found that larger hospitals (400 and more beds), relative to their smaller counterparts, were negatively associated with the likelihood of performing RARP (OR 0.53, $\mathrm{p}<0.001)$.
We performed sensitivity analysis by hospital surgery volume to test whether results systematically varied between high-volume and low-volume hospitals (table 4). Seventy-three RARP-performing hospitals were categorised into high volume if they performed more than 500 RARPs, medium volume if they performed between 200 and 499 RARPs, and low-volume if they performed 
Table 2 Patient characteristics within RARP-performing hospitals (model 2)*

\begin{tabular}{|c|c|c|c|}
\hline Variables & Non-RARP patients & RARP patients & p Valuet \\
\hline Number of patients (\%) & 2671 (16.3) & $13750(84.7)$ & \\
\hline Age $(\%)$ & & & 0.154 \\
\hline Younger than 55 & $429(16.5)$ & $2284(16.8)$ & \\
\hline $55-64$ & $1051(40.5)$ & $5766(42.4)$ & \\
\hline $65-74$ & 1020 (39.3) & 5117 (37.6) & \\
\hline 75 or older & $95(3.7)$ & $430(3.2)$ & \\
\hline Race (\%) & & & 0.362 \\
\hline Non-Hispanic white & $1692(72.5)$ & $9034(70.8)$ & \\
\hline Non-Hispanic black & $173(7.4)$ & $1048(8.2)$ & \\
\hline Hispanic & $283(12.1)$ & $1619(12.7)$ & \\
\hline Other & $186(8.0)$ & $1065(8.3)$ & \\
\hline Primary insurance (\%) & & & $<0.001$ \\
\hline Private & $1596(59.8)$ & $8673(63.1)$ & \\
\hline Medicare & 943 (35.3) & 5598 (33.9) & \\
\hline Medicaid & $72(2.7)$ & $185(1.4)$ & \\
\hline Other $\ddagger$ & $60(2.3)$ & $237(1.7)$ & \\
\hline Median household income (\%) & & & 0.798 \\
\hline Lowest quartile & $372(14.3)$ & $2014(15.1)$ & \\
\hline Middle-low quartile & $536(20.6)$ & $2724(20.4)$ & \\
\hline Middle-high quartile & $716(27.5)$ & $3666(27.4)$ & \\
\hline Highest quartile & $980(37.6)$ & 4982 (37.2) & \\
\hline Comorbidity index (\%) & & & 0.355 \\
\hline 0 & 1068 (40.0) & 5544 (40.3) & \\
\hline 1 & 887 (33.2) & 4696 (34.2) & \\
\hline 2 or greater & $716(26.8)$ & $3510(25.5)$ & \\
\hline Place of residence (\%) & & & 0.780 \\
\hline Metro & 2604 (97.7) & $13411(97.8)$ & \\
\hline Non-metro & $62(2.3)$ & $307(2.2)$ & \\
\hline Year & & & $<0.001$ \\
\hline 2009 & $1006(37.7)$ & 4068 (29.6) & \\
\hline 2010 & $960(35.9)$ & 4359 (31.7) & \\
\hline 2011 & $705(26.4)$ & $5323(38.7)$ & \\
\hline \multicolumn{4}{|c|}{$\begin{array}{l}\text { *For model 2, patient characteristics of robotic versus non-robotic surgery groups were compared within RARP-performing hospitals ( } \mathrm{n}=73 \text { ) } \\
\text { during the study period. Total patient sample size is } 16421 \text { for this model. } \\
\text { †Pearson's } \chi^{2} \text { test was conducted to test the proportional difference between robotic and non-robotic surgery groups within RARP-performing } \\
\text { hospitals. } \\
\text { †Other insurance includes self-pay, no charge, worker's compensation or other government and/or county indigent programmes. } \\
\text { RARP, Robot-assisted radical prostatectomy. }\end{array}$} \\
\hline
\end{tabular}

fewer than 200 RARPs during the study period. We found a significantly lower likelihood of undergoing RARP by Medicaid beneficiaries compared with those privately insured, only within high-volume hospitals and mediumvolume hospitals (AOR 0.09 and 0.51, $\mathrm{p}<0.001$ and $\mathrm{p}<0.03$, respectively).

\section{DISCUSSION}

By using SID-AHA merged data from 2009 to 2011 in California, we examined patient and hospital characteristics associated with (1) accessing an RARP-performing versus non-RARP-performing hospital and (2) patient receipt of RARP within hospitals performing RARP. Despite the rapid increase in the use of RARP during the last decade, our analysis showed that potential benefits from this advanced surgical technology were not equally distributed among patient subgroups in California at either the hospital level or the individual patient level. For example, Hispanic ethnicity, Medicare/Medicaid insurance, low socioeconomic status and non-metro residence status were negatively associated with access to an RARP-performing hospital. An analysis of RARP-performing hospitals further suggested that Medicaid patients were less likely to receive RARP than were privately insured patients, even after adjusting for selected confounding factors.

Our study findings highlight that racial and socioeconomic disparities exist in accessing an RARP-performing hospital, after controlling for selected patient and hospital characteristics. We defined an RARP-performing hospital as a hospital which performed at least one RARP from 2009 to 2011, using all inpatient data available in the California SID database. In our study, RARP-performing hospitals compared with non-RARP-performing hospitals were generally larger, more likely to be not-for-profit, have teaching status, and be located in an urban area. These findings are 
Table 3 Adjusted ORs (AORs) of receiving RARP versus Non-RARP by patient and hospital characteristics

\begin{tabular}{|c|c|c|c|c|}
\hline & \multicolumn{2}{|c|}{ Model 1 (all hospitals*) } & \multicolumn{2}{|c|}{$\begin{array}{l}\text { Model } 2 \text { (RARP-performing } \\
\text { hospitals } † \text { ) }\end{array}$} \\
\hline & AOR $(95 \% \mathrm{Cl})$ & p Value & AOR (95\% Cl) & p Value \\
\hline \multicolumn{5}{|l|}{ Independent variables } \\
\hline \multicolumn{5}{|l|}{ Age (years) } \\
\hline Less than 55 (ref.) & - & - & - & - \\
\hline $55-64$ & $0.83(0.72 \text { to } 0.94)^{\star *}$ & 0.004 & 0.94 (0.81 to 1.08$)$ & 0.361 \\
\hline $65-74$ & 1.01 (0.85 to 1.20$)$ & 0.933 & 0.90 (0.75 to 1.08$)$ & 0.250 \\
\hline 75 and older & $1.50(1.08 \text { to } 2.07)^{\star}$ & 0.015 & 0.93 (0.67 to 1.29$)$ & 0.643 \\
\hline \multicolumn{5}{|l|}{ Race/ethnicity } \\
\hline Non-Hispanic white (ref.) & - & - & - & - \\
\hline Non-Hispanic black & 1.14 (0.98 to 1.33$)$ & 0.091 & 1.08 (0.90 to 1.29$)$ & 0.431 \\
\hline Hispanic & $0.63(0.56 \text { to } 0.70)^{\star *}$ & $<0.001$ & 1.01 (0.87 to 1.17$)$ & 0.929 \\
\hline Other & 0.93 (0.79 to 1.09$)$ & 0.353 & $1.12(0.94$ to 1.33$)$ & 0.197 \\
\hline \multicolumn{5}{|l|}{ Insurance } \\
\hline Private (ref.) & - & - & - & - \\
\hline Medicare & $0.71(0.62 \text { to } 0.82)^{\star *}$ & $<0.001$ & $0.93(0.80$ to 1.08$)$ & 0.342 \\
\hline Medicaid & $0.14(0.11 \text { to } 0.19)^{\star *}$ & $<0.001$ & $0.42(0.31 \text { to } 0.58)^{\star \star}$ & $<0.0001$ \\
\hline Other $\ddagger$ & $0.09(0.07 \text { to } 0.12)^{\star *}$ & $<0.001$ & 0.75 (0.53 to 1.06$)$ & 0.107 \\
\hline \multicolumn{5}{|l|}{ Median household income } \\
\hline 1, lowest (ref.) & - & - & - & - \\
\hline 2 , middle-low & $1.17(1.03 \text { to } 1.33)^{*}$ & 0.018 & 0.93 (0.79 to 1.09$)$ & 0.346 \\
\hline 3, middle-high & $1.26(1.11 \text { to } 1.43)^{\star *}$ & 0.0004 & $0.84(0.72 \text { to } 0.98)^{*}$ & 0.025 \\
\hline 4, highest & $1.90(1.67 \text { to } 2.17)^{\star *}$ & $<0.001$ & $0.89(0.77$ to 1.04$)$ & 0.137 \\
\hline \multicolumn{5}{|l|}{ Comorbidity index } \\
\hline 0 (ref.) & - & - & - & - \\
\hline 1 & $0.71(0.64 \text { to } 0.79)^{\star *}$ & $<0.001$ & $0.89(0.79 \text { to } 0.99)^{*}$ & 0.028 \\
\hline 2 or greater & $0.54(0.49 \text { to } 0.60)^{\star *}$ & $<0.001$ & $0.80(0.71 \text { to } 0.90)^{\star \star}$ & 0.001 \\
\hline \multicolumn{5}{|l|}{ Place of residence } \\
\hline Metro (ref.) & - & - & - & - \\
\hline Non-metro & $0.28(0.22 \text { to } 0.36)^{\star \star}$ & $<0.001$ & 1.15 (0.82 to 1.62$)$ & 0.404 \\
\hline \multicolumn{5}{|l|}{ Hospital ownership } \\
\hline Not-for-profit (ref.) & - & - & - & - \\
\hline For-profit & $0.32(0.27 \text { to } 0.38)^{\star *}$ & $<0.001$ & $0.40(0.31 \text { to } 0.52)^{\star \star}$ & $<0.0001$ \\
\hline Government & $1.23(1.07 \text { to } 1.41)^{\star *}$ & 0.003 & $0.51(0.46 \text { to } 0.58)^{\star *}$ & $<0.0001$ \\
\hline \multicolumn{5}{|l|}{ Teaching status } \\
\hline Non-teaching (ref.) & - & - & - & - \\
\hline Teaching§ & $4.75(4.16 \text { to } 5.41)^{\star *}$ & $<0.001$ & $1.65(1.49 \text { to } 1.83)^{\star *}$ & $<0.0001$ \\
\hline \multicolumn{5}{|l|}{ Hospital bed size } \\
\hline 0-399 (ref.) & - & - & - & - \\
\hline 400 and more & $7.06(6.03 \text { to } 8.27)^{\star *}$ & $<0.001$ & $0.53(0.48 \text { to } 0.59)^{\star \star}$ & $<0.0001$ \\
\hline \multicolumn{5}{|l|}{ Year } \\
\hline 2009 (ref.) & - & - & - & - \\
\hline 2010 & $1.30(1.18 \text { to } 1.44)^{\star *}$ & $<0.001$ & $1.16(1.05 \text { to } 1.30)^{\star *}$ & 0.006 \\
\hline 2011 & $1.87(1.68 \text { to } 2.08)^{\star \star}$ & $<0.001$ & $2.03(1.82 \text { to } 2.28)^{\star \star}$ & $<0.001$ \\
\hline \multicolumn{5}{|l|}{ Sample size } \\
\hline Hospital & 225 & & 73 & \\
\hline Patient & 18101 & & 14679 & \\
\hline \multicolumn{5}{|c|}{$\begin{array}{l}\text { *Dependent variable for model } 1 \text { (all hospital model) was a hospital-level robotic surgery binary code ( }=1 \text { if a hospital performed at least one } \\
\text { RARP). } \\
\text { †Dependent variable for model } 2 \text { (RARP-performing hospital model) was a patient-level robotic surgery binary code ( }=1 \text { if a patient underwent } \\
\text { RARP). } \\
\text { fOther insurance includes self-pay, no charge, worker's compensation, or other government and/or county indigent programmes. } \\
\text { §Teaching status was obtained from the AHA annual survey } 2009 \text { (member of the Council of Teaching Hospitals of the Association of } \\
\text { American Medical Colleges. } \\
\text { ”p<0.05; } \\
\text { RARP, Robot-assisted radical prostatectomy. }\end{array}$} \\
\hline
\end{tabular}

consistent with previous cancer care studies of the characteristics of high surgical volume hospitals. ${ }^{13-14} 21-23$
Moreover, RP markets are becoming more centralised, by regionalising RP treatments within limited geographic 
Table 4 Adjusted ORs (AORs) of RARP versus non-RARP by patient characteristics stratified by hospital RARP surgery volume

\begin{tabular}{|c|c|c|c|c|c|}
\hline $\begin{array}{l}\text { High-RARP-volume } \\
\text { ( } \geq 500 \text { cases) }\end{array}$ & & $\begin{array}{l}\text { Medium-RARP-volume } \\
\text { (200-499 cases) }\end{array}$ & & $\begin{array}{l}\text { Low-RARP-volume } \\
\text { ( } \leq 199 \text { cases) }\end{array}$ & \\
\hline AOR (95\% Cl) & p Value & AOR (95\% CI) & p Value & AOR (95\% CI) & p Value \\
\hline
\end{tabular}

\section{Independent variables}

Race/ethnicity (ref.=non-Hispanic white)

Non-Hispanic black $0.87(0.560$ to 1.358$)$

Hispanic $\quad 0.96(0.611$ to 1.517$)$

$0.545 \quad 0.94(0.643$ to 1.381$)$

$0.871 \quad 1.04(0.794$ to 1.367$)$

Other

1.47 (0.873 to 2.484 )

0.147

$1.02(0.777$ to 1.340$)$

0.760

0.86 (0.654 to 1.129$)$

0.767

0.885

0.93 (0.752 to 1.152$)$

1.21 (0.916 to 1.595$)$

0.277

0.509

Insurance (ref.=private)

Medicare

Medicaid

0.78 (0.505 to 1.205$)$

0.264

$<0.001$

0.85 (0.649 to 1.119$)$

$0.51(0.280 \text { to } 0.915)^{*}$

0.38 (0.176 to 0.840$)^{*}$

0.017

0.64 (0.395 to 1.049 )

0.250

$0.97(0.775$ to 1.204$)$

0.024

$1.27(0.759$ to 2.116$)$

0.077

1.28 (0.631 to 2.597$)$

0.755

Median household Income (ref.=1, lowest)
2, middle-low
0.79 (0.510 to 1.227$)$
3, middle-high
0.96 (0.634 to 1.450$)$
4, highest

Sample size

Hospital

Patient
0.295

0.843

$0.90(0.657$ to 1.228$)$ *

$0.53(0.393 \text { to } 0.707)^{\star *}$

0.500

0.014

$<0.001$
0.99 (0.787 to 1.253$) \quad 0.053$

0.81 (0.642 to 1.018$) \quad 0.071$

$0.72(0.572 \text { to } 0.913)^{\star \star} \quad 0.007$

Dependent variable is a binary code of receiving RARP $(=1)$ versus not receiving RARP $(=0)$.

High-volume hospitals are those that performed more than 500 RARPs during the study period, medium-volume-hospitals are those that performed between 200 and 499 RARPs during the study period, and low-volume-hospitals are those that performed fewer than 200 RARPs during the study period. Results are also adjusted for patient's age, geographic location, comorbidity, year of the procedure, and hospital characteristics (ownership, teaching status, bed size).

†Dependent variables for model 2 (RARP-performing hospital model) was a patient-level robotic surgery binary code (=1 if a patient underwent RARP).

${ }^{*} p<0.05 ;{ }^{* *} p<0.01$.

RARP, Robot-assisted radical prostatectomy.

areas. ${ }^{24}$ The regionalisation of RP hospitals has increased patient's mean travel time to health facilities, ${ }^{15}$ which may further exacerbate disparities in access to care for minorities and lower income patients, who may have transportation limitations. To the best of our knowledge, previous studies have not examined the centralisation of care in California. Our sensitivity analysis by volume showed that only six hospitals were providing more than 500 RARP cases during the 3-year study period. More detailed studies are needed to understand the impact of centralisation of RP services and the association with access issues for minority populations.

Different patterns of patient referral among racial and socioeconomic subgroups can be another factor affecting differential access. Selective referral to high-volume urologists or hospitals has been advocated to improve quality of surgical care. ${ }^{16}$ However, recent studies found that racial minorities and patients with lower socioeconomic status were less likely to have access to high-volume facilities ${ }^{23}$ or hospitals with advanced technology ${ }^{25}$ A recent study revealed that African-American men with PC were less likely to be treated by highvolume urologists even though both African-American and Caucasian men had an equal chance of being diagnosed by high-volume urologists. ${ }^{14}$ More research is needed to understand mechanisms of referral patterns of Hispanics and their association with lower socioeconomic status in accessing an RARP-performing hospital.
We further examined within-hospital variation in the utilisation of RARP across patient subgroups to identify factors that are predictive of use of RARP versus non-RARP procedures. Compared to privately insured patients, we found Medicaid patients to have substantially lower adjusted odds of receiving RARP within an RARP-performing hospital. This disparity was further magnified in that Medicaid beneficiaries were less likely to have access to an RARP-performing hospital in the first place. Furthermore, the differential likelihood of receiving RARP by payer type was largest in high-RARP-volume hospitals. Our results have important implications in the context of the Affordable Care Act (ACA) because many states, including California, have expanded the eligibility for Medicaid under the ACA. Consequently, we expect that disparities in both access to an RARP-performing hospital and receipt of RARP within an RARP-performing hospital may increase further as the number of Medicaid enrollees grows over time.

Differential use of RARP by payer type could be related to quality of care for patients unable to access RARP. A recent study investigating $61167 \mathrm{RP}$ cases in the USA during 2003-2007 showed that patients with Medicaid and Medicare had higher rates of blood transfusion, greater overall postoperative complications, longer hospital stays, and higher in-hospital mortality compared to those with private insurance. ${ }^{12}$ Although the authors did not distinguish between robotic versus non-robotic surgery in their study, our study found that 
private insurance status is associated with higher levels of utilisation of robotic surgery for RP patients, consistent with the previous study. ${ }^{14}$ Therefore, Medicaid patients, who had relatively lower odds of receiving RARP in our study, may have worse post-treatment outcomes than those with private insurance. Of course, Medicaid or uninsured patients may have higher risks of in-hospital mortality/morbidity and longer hospital stays. ${ }^{12}$ To answer this question-that is, whether Medicaid patients who receive robotic surgery have better or worse outcomes than Medicaid patients who receive non-robotic surgery-future research should compare outcomes of RARP versus non-RARP stratified by patients' insurance status, adjusting for confounding factors.

Our study does have a few limitations. First, the study used administrative records of all RP patients for the State of California. Our data lacks preoperative patient characteristics, as well as long-term oncological or functional outcomes, which may partially explain the relationship between patient characteristics and the decision to use RARP versus ORP or LRP. Second, our study did not consider cultural factors associated with different racial/ethnic groups. It is possible that Hispanic patients may have lower preference of seeking 'high-tech' care and ended up with having less travel to 'high-tech' hospitals when the nearest hospitals do not offer robotic surgery. However, these measures (ie, individual preference or home-to-hospital distance) are not available in our current data, but remains to be explored in future studies. Finally, the generalisability of the study findings may be limited to a single state. California has more than twice the Hispanic population (38\%) when compared with the US average $(17 \%) .{ }^{26}$ This factor may have an effect on our findings of significant racial differences between Hispanics and non-Hispanic whites. Our study findings should be generalised with caution, particularly for those states with higher African-American populations or lower Hispanic populations. Nevertheless, given that California is the most populous state (38 million by a 2014 estimate) ${ }^{26}$ with a sizable RP population (20 411 cases for a 3-year study period), and a representative RARP rate $(67 \%$ for 3-year study period), it provided our research team with a very large sample to conduct our analysis. Additionally, to the extent that health disparities in California are presumably more substantial than the national average, ${ }^{27}$ our data containing all the population-level inpatient records in California may yield more robust inference for local decision-makers. Further research focusing on racial/ethnic disparities in the use of RARP needs to be conducted in other states to improve the generalisability of these study findings.

Our study findings have significant clinical implications. The lack of access to an RARP hospital or RARP procedures within RARP-performing hospital may imply less ideal care for the Hispanic minority and patients with lower socioeconomic status, if benefit of RARP exceeds LRP or ORP. Currently, no definitive evidence supports a clinical advantage of the use of RARP compared with open or laparoscopic surgery. Recent studies have shown that RARP has similar or only marginal improvements in outcomes. ${ }^{6} \quad 7 \quad 28-30$ Additionally, research findings about the cost-effectiveness of RARP are inconclusive. ${ }^{30-33}$ Randomised clinical trials (RCT) are often recommended as powerful tools to provide the highest level of scientific evidence of cause-and-effect relationship between an intervention and outcomes. However, conducting RCTs can be challenging given that at least $85 \%$ of the RP cases are now robotic in the USA. $^{2}$ Diverse, innovative approaches with advanced statistical methodologies and longitudinal functional outcomes will be needed to provide more robust evidence of the potential benefits of RARP versus ORP or LRP.

\section{CONCLUSIONS}

Despite the rapid increase in the use of RARP in the past decade, our analysis showed that this growth may not have been equally distributed throughout the patient population. Hispanic ethnicity, Medicare/Medicaid insurance, low socioeconomic status and non-metro location were negatively associated with access to an RARPperforming hospital. Even within RARP-performing hospitals, Medicaid patients are less likely to receive RARP versus other non-robotic procedures than are privately insured patients, after adjusting for selected confounding factors. Our study results suggest that both access to an RARP-performing hospital and differential access to RARP within an RARP-performing hospital are important sources of potential future disparities, particularly for Medicaid patients in high-RARP-volume hospitals.

Acknowledgements The authors would like to thank Dr Onook Oh, Dr Hongmei Wang and Dr Mohammad Siahpush for their inspiration, support and encouragement for this study.

Contributors JK conceptualised and designed the study, conducted data analysis and interpreted the results, drafted the manuscript and edited the manuscript for important content. WE assisted in the data management and analysis, conducted literature review and edited the manuscript for important content. FW provided the data, interpreted the results and edited the manuscript for important content. DS, DO and MM edited the manuscripts for important content. L-WC assisted in the conceptualisation and the design of the study, and edited the manuscript for important content.

Funding This research received no specific grant from any funding agency in the public, commercial, or not-for-profit sectors.

\section{Competing interests None declared.}

Ethics approval The University of Nebraska Medical Center Internal Review Board determined that the study does not constitute human subject research due to the use of de-identified patient records of publicly available secondary data.

Provenance and peer review Not commissioned; externally peer reviewed.

Data sharing statement The study used secondary data which is publicly available.

Open Access This is an Open Access article distributed in accordance with the Creative Commons Attribution Non Commercial (CC BY-NC 4.0) license, which permits others to distribute, remix, adapt, build upon this work noncommercially, and license their derivative works on different terms, provided 
the original work is properly cited and the use is non-commercial. See: http:// creativecommons.org/licenses/by-nc/4.0/

\section{REFERENCES}

1. Phillips $C$. Tracking the rise of robotic surgery for prostate cancer. Natl Cancer Inst Cancer Bull 2011;8:16.

2. Lowrance WT, Eastham JA, Savage C, et al. Contemporary open and robotic radical prostatectomy practice patterns among urologists in the United States. J Urol 2012;187:2087.

3. Ostrom CM. Use of surgical robots booming despite hefty cost. Seattle Times 7 July 2012. http://seattletimes.com/html/localnews/ 2018631542 robot08m.html

4. Berryhill R Jr, Jhaveri J, Yadav R, et al. Robotic prostatectomy: a review of outcomes compared with laparoscopic and open approaches. Urology 2008;72:15.

5. Anderson JE, Chang DC, Parsons JK, et al. The first national examination of outcomes and trends in robotic surgery in the United States. J Am Coll Surg 2012;215:107.

6. Gandaglia G, Sammon JD, Chang SL, et al. Comparative effectiveness of robot-assisted and open radical prostatectomy in the postdissemination era. J Clin Oncol 2014;32:1419.

7. Moran PS, O'Neill M, Teljeur C, et al. Robot-assisted radical prostatectomy compared with open and laparoscopic approaches: a systematic review and meta-analysis. Int J Urol 2013;20:312.

8. Yu H, Hevelone ND, Lipsitz SR, et al. Use, costs and comparative effectiveness of robotic assisted, laparoscopic and open urological surgery. J Urol 2012;187:1392.

9. Trinh Q, Schmitges J, Sun M, et al. Improvement of racial disparities with respect to the utilization of minimally invasive radical prostatectomy in the United States. Cancer 2012;118:1894.

10. Shavers VL, Brown ML, Potosky AL, et al. Race/ethnicity and the receipt of watchful waiting for the initial management of prostate cancer. J Gen Intern Med 2004;19:146.

11. Liu JH, Zingmond DS, McGory ML, et al. Disparities in the utilization of high-volume hospitals for complex surgery. JAMA 2006;296:1973.

12. Trinh $Q$, Schmitges J, Sun $M$, et al. Morbidity and mortality of radical prostatectomy differs by insurance status. Cancer 2012;118:1803.

13. Kim SP, Boorjian SA, Shah ND, et al. Disparities in access to hospitals with robotic surgery for patients with prostate cancer undergoing radical prostatectomy. J Urol 2013;189:514.

14. Pollack CE, Bekelman JE, Epstein AJ, et al. Racial disparities in changing to a high-volume urologist among men with localized prostate cancer. Med Care 2011;49:999-1006.

15. Stitzenberg KB, Wong $\mathrm{Y}$, Nielsen ME, et al. Trends in radical prostatectomy: centralization, robotics, and access to urologic cancer care. Cancer 2012;118:54.
16. Dudley RA, Johansen KL, Brand R, et al. Selective referral to high-volume hospitals: estimating potentially avoidable deaths. JAMA 2000;283:1159.

17. The Health Care Cost and Utilization Project: State Inpatient Sample. http://www.hcup-us.ahrq.gov/sidoverview.jsp (accessed 1 Sep 2014).

18. The AHA annual survey. 2009. http://www.ahadataviewer.com/ book-cd-products/aha-survey (accessed 1 Apr 2014).

19. Nielsen SiteReports. Online Source for ZIP-code based State Income. http://www.claritas.com/sitereports/Default.jsp (accessed 12 Mar 2015).

20. Elixhauser A, Steiner C, Harris DR, et al. Comorbidity measures for use with administrative data. Med Care 1998;36:8.

21. Dimick JB, Cowan JA Jr, Colletti LM, et al. Hospital teaching status and outcomes of complex surgical procedures in the United States. Arch Surg 2004;139:137.

22. Keeler EB, Rubenstein LV, Kahn KL, et al. Hospital characteristics and quality of care. JAMA 1992;268:1709.

23. Sun M, Karakiewicz PI, Sammon JD, et al. Disparities in selective referral for cancer surgeries: Implications for the current healthcare delivery system. BMJ Open 2014;4:e003921.

24. Anderson CB, Penson DF, Ni S, et al. Centralization of radical prostatectomy in the United States. J Urol 2013;189:500.

25. Blustein J, Weitzman BC. Access to hospitals with high-technology cardiac services: how is race important? Am J Public Health 1995;85:345.

26. U.S. Census Bureau. State and County Quick Facts 2014 Estimates. http://quickfacts.census.gov/qfd/states/06000.html (accessed 12 Mar 2015).

27. Sommeiller E, Price M. The increasingly unequal States of America. Vol. 19. Economic Policy Institute 2014.

28. Coelho RF, Rocco B, Patel MB, et al. Retropubic, laparoscopic, and robot-assisted radical prostatectomy: a critical review of outcomes reported by high-volume centers. J Endourol 2010;24:2003.

29. Ficarra V, Novara G, Ahlering TE, et al. Systematic review and meta-analysis of studies reporting potency rates after robot-assisted radical prostatectomy. Eur Urol 2012;62:418.

30. Ficarra V, Novara G, Rosen RC, et al. Systematic review and meta-analysis of studies reporting urinary continence recovery after robot-assisted radical prostatectomy. Eur Urol 2012;62:405

31. Bolenz C, Freedland SJ, Hollenbeck BK, et al. Costs of radical prostatectomy for prostate cancer: a systematic review. Eur Urol 2014;65:316.

32. Hohwü L, Borre M, Ehlers L, et al. A short-term cost-effectiveness study comparing robot-assisted laparoscopic and open retropubic radical prostatectomy. J Med Econ 2011;14:403.

33. Stewart BS, Reed SD, Moul JW. Will the future of health care lead to the end of the robotic golden years? Eur Urol 2014;65:325. 